
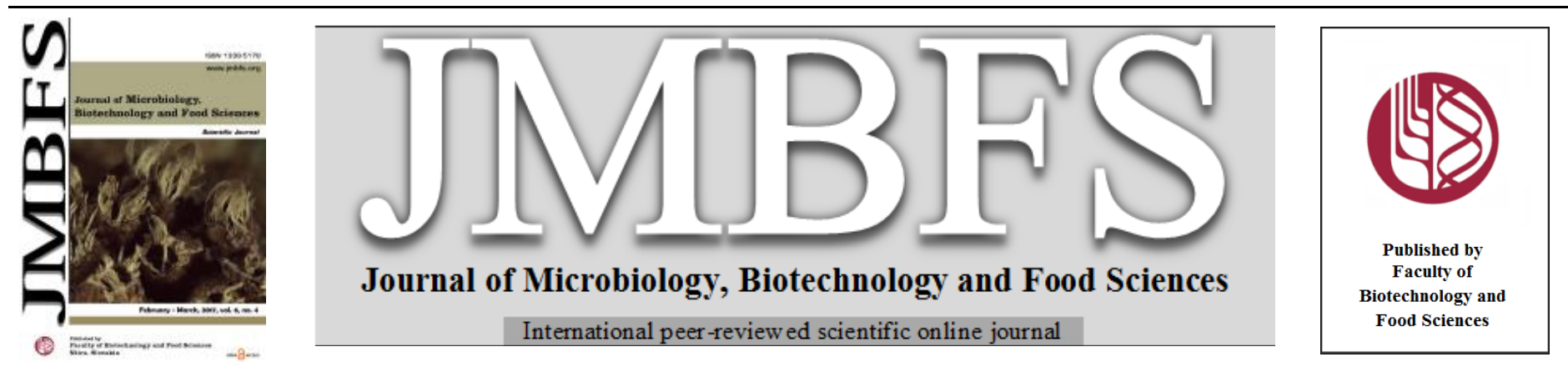

\title{
INTERACTION OF SEMI-REFINED CARRAGEENAN (E407A) WITH NANO QUANTA OF SOME FOOD HYDROCOLLOIDS AND THEIR PHYSIOCHEMICAL, FUNCTIONAL AND RHEOLOGICAL PROPERTIES
}

\author{
Murugesan Marimuthu, Packrisamy Ilansuriyan, Tony N Yap, Munisamy Shanmugam *
}

Address(es): Dr. Munisamy Shanmugam,

Food Ingredients Group, Research and Development Division, AquAgri Processing Private Limited, B5, SIPCOT Industrial Complex, Manamadurai - 630 606, Sivaganga District, Tamil Nadu, INDIA.

*Corresponding author: m.shanmugam@aquagri.in

doi: 10.15414/jmbfs.2017.6.4.1049-1053

\section{ARTICLE INFO}

Received 15. 4. 2016

Revised 22. 11. 2016

Accepted 5. 12. 2016

Published 1. 2. 2017

Regular article

OPEN $\partial_{\text {ACCESS }}$

\section{ABSTRACT}

Interaction of semi-refined carrageenan with other food hydrocolloids in different ratio and their rheological, physicochemical and some functional characteristics were evaluated in the present study. Gel strength and viscous synergism index $\left(\mathrm{I}_{\mathrm{v}}\right)$ were measured and used to analyze their interaction level. Kappa carrageenan had good synergistic effect with cassia, LBG, guar, HPMC and konjac and antagonistic effect with xanthan, alginate, CMC and agar. Only Iota carrageenan in the range of 60:40 with kappa showed neutral effect. A blend of SRC with konjac / LBG can be made for good gel strength whereas konjac / GG for good viscosity. Therefore, SRC can be used in place of refined carrageenan in some food applications.

Keywords: Semi-refined carrageenan, Food hydrocolloids, Synergism index, Gel strength, Viscosity, Water holding capacity, Emulsifying Activity

\section{INTRODUCTION}

Hydrocolloids are a heterogeneous group of long chain polysaccharides and proteins. When it fuses with water, it forms colloid which is between a true solution and suspension. The number of hydroxyl group indicate the increases their affinity towards water binding and acted as a hydrophilic compound. Hydrocolloids offer food formulators a strong value proposition, based on a unique synergy with other hydrocolloids and protein. Depending upon their origin, hydrocolloids can be classified as Natural, Semi-synthetic and Synthetic. The naturally (vegetable) derived hydrocolloids are mainly used as oil in water emulsifiers; whereas, animal derived hydrocolloids form water in oil emulsion. Most hydrocolloids derived from a plant source and remaining from microbial fermentation and others are the result of chemical modification of natura polysaccharide. A great number of synthetic and semi synthetic hydrocolloids along with natural using in food Industry (Saha $\mathbb{\&}$ Bhattacharya, 2010).

Nanotechnology is an advanced technology that has the capacity to modify the food sector (Luykx et al., 2008; Huang et al., 2010). The application of nanotechnology to the food sector focus on color, taste, texture, sensory attributes and stability during shelf life. In addition, it improves the thermal stability, water solubility and oral bioavailability of functional compounds (McClements $\boldsymbol{e t}$ al. 2009) Nano emulsions derived from the natural hydrocolloids act as colloidal drug carriers for pharmaceutical applications. Due to best internal absorption, the bioavailability of less water soluble drugs increases even though it passes through oral way (Constantinides, 1995; Bates et al., 1975).Absorption in the gastrointestinal tract is improved by a small droplet size also been found (Toguchi et al., 1990). Recently, more preferences have been given for the use of many natural hydrocolloids as drug delivery carriers in the bio-pharmaceutical sector (Ogaji et al., 2012).

In food industries, hydrocolloids play a dominant inevitable role especially as thickeners and stabilizing agent. Currently, carrageenans such as kappa and ioto have an important share in the pudding and milk shakes (Puvanenthiran et al., 2003). As we known the Agar-Agar, oldest one plays the main role in the bakery products and jelly industries commercially (Stanley, 2006). Alginate used as the best ingredient in the restructured food and cold prepared bakery creams (Roopa et al., 2009). In fruit juice beverages and soft drinks, hydroxyl propyl methyl cellulose used extensively (Williams \& Philips, 2000). Konjac highly used in extruded product like noodles and also in jelly desserts (Williams, 2006). Due to high viscous and texture stabilizing nature Locust bean gum and Guar gum used in the various sectors such as ice cream, ketchup, fruit juice and pudding powder
(Koocheki et al., 2009). Xanthan gum and carboxyl methyl cellulose play the main role in the soups, ketchup and gravies (Sahin et al., 2004).

Hydrocolloid market, which has been growing at compound annual growth rate (CAGR \%) of $12 \% \pm 3 \%$ in recent years, is valued at around $\$ 4.4$ billion p.a. with a total volume of about 260,000 tons (Kayacier et al., 2006). In the food industry, combined hydrocolloids and their formulation have been proven successfully at the various industrial products during and after processing. Their properties mostly depend on individual hydrocolloid properties. Mixed hydrocolloids give strong synergistic effects than the individual one. For this reason, many researchers focused on the rheological characteristics of combined hydrocolloids (Walkenstrom et al., 2003; Mandala et al., 2003). The objective of present study was to investigate the interaction of Semi-Refined Carrageenan (E407a) with nano sized dosage of some mood hydrocolloids and their physiochemical, functional and rheological properties.

\section{MATERIAL AND METHODS}

\section{Materials}

The ingredients of food grade carrageenan (E 407a) (Kappa, Iota) used were from the stock of AquAgri Processing Private Limited, Batch No-108/2015, Manamadurai, Tamil Nadu, India. Locust bean gum (LBG, E 410) (R.K Enterprises, India), Guar gum (GG, E 412) (Sarda Gums \& Chemicals, India), Sodium carboxymethyl cellulose (CMC, E 466) (Wealthy Chemicals Industry, Suzhou, China), Konjac gum (E 425) (Shanghai Research Institute of Chemical Industry Testing Centre, China), Na-Alginate (E 401) (SNAP Alginate, India), Gelatine (E 441) (Nice Chemical Private Limited, Kerala, India), Hydroxy Propyl Methyl Cellulose (HPMC, E15) (LOBA Chemicals Private Limited, Mumbai, India), Agar-Agar (E 406) (Marine chemicals, Cochin, India), Cassia gum (E 427) (Swastik Gums, India) and Xanthan gum (E 415) were purchased from Ziboxan, Deosen Biochemical Limited, China. Equipments used were: Brookfield texture analyzer, Model CT3 4500, USA; Remi motor-RQ 122, Remi Elektrotechnik Limited, India; Water bath-250 W, Sigma Scientific Instrument Private Limited, Chennai, India; Samsung Refrigerator, Model RR 19 H1104RH/DL, India and Sony Cyber shot, GPS- DSC- HX 200.

\section{Measurement of Gel strength and Viscosity}

A $1.5 \mathrm{~g}$ hydrocolloid sample was weighed and incorporated slowly into $100 \mathrm{ml}$ distilled water and the solution was stirred on a water bath at $80^{\circ} \mathrm{C}$ till to get a 
complete dissolution of hydrocolloids. After heat treatment, solution was analyzed immediately at $75^{\circ} \mathrm{C}$ for viscosity (Brookfield LVD-II+P viscometer, Brookfield Engineering Laboratories, Inc., MA, USA) and gel strength was measured after maintain $20 \pm 2{ }^{\circ} \mathrm{C}$ storage for overnight in Brookfield texture analyzer (CT3 Texture Analyzer, Brookfield Engineering Laboratories, Inc., MA, USA).

\section{Physicochemical analysis}

Moisture, Ash content of each hydrocolloid sample was determined by the gravimetric method. $\mathrm{pH}$ values of samples were measured with a $\mathrm{pH}$ meter (Eutech Instruments, Malaysia) in their solutions prepared with distilled water $(1.5 \% \mathrm{w} / \mathrm{v})$. Bulk density of hydrocolloids particle was measured by method of Okara et al. (1977)

\section{Rheological analysis}

Calculation of expected viscosity of binary gum mixtures at equal concentration in a solution was expressed as Eq.3 and Eq.4 (Rao, 1999).

mix $=X_{A} \eta_{A}+X_{B} \eta_{B}$

$\eta_{\text {mix }}=\eta A^{X A} * \eta_{B}^{X B}$

Where $X A$ and $X B$ are the weight fractions of gum $\mathrm{A}$ and $\mathrm{B}$, respectively, and $\eta A$ and $\eta B$ are the apparent viscosity of sole gum $\mathrm{A}$ and $\mathrm{B}$ solutions at the same concentration.Viscous synergism index (Iv) was calculated using the following expression in Eq.5 as described by Pellicer et al., (2000) as below

$$
I v=\eta i+j / \eta i+\eta j
$$

Where $\mathrm{i}$ and $\mathrm{j}$ represent the two hydrocolloids present in the blend $(\mathrm{i}+\mathrm{j})$

\section{Functional property analysis}

\section{Water-holding Capacity (WHC) and Oil-holding Capacity (OHC)}

WHC and OHC were determined according to methods described by Robertson et al (2000). Distilled water / commercial olive oil (25 mL) was added to $250 \mathrm{mg}$ of dry sample, stirred and left at room temperature for $1 \mathrm{~h}$. After centrifugation, the residue was weighed. The WHC was expressed as $g$ of water held per $g$ of sample, while the $\mathrm{OHC}$ was expressed as $\mathrm{g}$ of oil held per $\mathrm{g}$ of sample.

\section{Emulsifying Activity (EA) and Emulsion Stability (ES)}

A DIAX 900 Heidolph homogenizer (Schwabach, Germany) was used to homogenize a $2 \%(\mathrm{w} / \mathrm{v})$ sample suspension in water at $11,000 \mathrm{rpm}$ for $30 \mathrm{~s}$ Sunflower oil $(100 \mathrm{~mL})$ was then added and homogenized for another $1 \mathrm{~min}$. The emulsions were centrifuged in $15 \mathrm{~mL}$ graduated centrifuge tubes at 1,200 $\mathrm{g}$ for 5 min, and the volume of the emulsion left was measured. To determine the ES, emulsions prepared by the above procedures were heated at $80^{\circ} \mathrm{C}$ for $30 \mathrm{~min}$ and cooled to room temperature, and centrifuged at 1,200 $\mathrm{g}$ for $5 \mathrm{~min}$. EA and ES were calculated using the following equations (Chau et al., 1997).

$$
\begin{aligned}
& \text { Volume of emulsified layer (mL) } \\
& \text { EA = ---------------- X } 100 \\
& \text { Volume of remaining emulsified layer }(\mathrm{mL})
\end{aligned}
$$

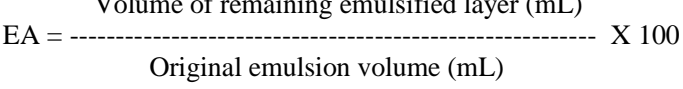

\section{RESULTS AND DISCUSSION}

\section{Physiochemical properties}

The physiochemical parameters of hydrocolloids play an important role in the food and pharmaceutical application. The moisture, $\mathrm{pH}$, bulk density, viscosity, gel strength and ash content of all the individual hydrocolloids shown in Table 1.

Table 1 Physiochemical properties of some food hydrocolloids

\begin{tabular}{lllllll}
\hline Hydrocolloids & Moisture & Ash & $\mathrm{pH}$ & Bulk density & Viscosity & $\begin{array}{l}\text { Gel strength } \\
\left(\mathrm{g} / \mathrm{cm}^{2}\right)\end{array}$ \\
\hline K-Carrageenan & 9.27 & 6.97 & 8.5 & 0.795 & 10 & 690 \\
Ca-Iota & 7.60 & 6.91 & 9.62 & 0.875 & 50 & - \\
LBG & 5.23 & 9.90 & 6.81 & 0.653 & 4700 & - \\
Guar Gum & 9.14 & 9.92 & 6.45 & 0.715 & 7250 & - \\
Gelatin & 9.60 & 9.93 & 5.47 & 0.601 & 5 & - \\
Agar-Agar & 9.68 & 8.90 & 6.12 & 0.712 & 2 & 485 \\
Na-Alginate & 11.84 & 7.13 & 7.42 & 0.947 & 60 & - \\
Xanthan gum & 9.56 & 9.09 & 6.21 & 0.729 & 4500 & - \\
Cassia Gum & 7.42 & 9.90 & 6.04 & 0.700 & 30 & - \\
Na-CMC & 11.20 & 8.22 & 7.72 & 0.666 & 6100 & - \\
Konjac Gum & 7.92 & 4.82 & 6.04 & 0.712 & 7800 & - \\
HPMC & 3.42 & 9.93 & 6.45 & 0.658 & 12 & - \\
\hline
\end{tabular}

\section{Properties of combined food hydrocolloids}

\section{pH}

The $\mathrm{pH}$ value of different gums like Konjac gum Guar gum, LBG, Iotacarrageenan, Xanthan, Na-Alginate, Gelatine, Cassia gum, Na-CMC, HPMC and Agar-Agar with Kappa-carrageenan showed in Table 1. From a consideration of $\mathrm{pH}$, along with the interaction of different food hydrocolloids were studied as shown in Figure 1. kappa carrageenan has been blended with gums with a ratio of 20:80, 40:60, 60:40 \& 80:20. All from those blending the pH level of Iota decreases from 9.67 to 9.22 ; this is due to the fact that Iota carrageenan has higher $\mathrm{pH}$ value when compared to kappa carrageenan. So with the combination of this ratio's Iota-carrageenan has different property compared to other hydrocolloids. Whereas, viscous gums like Guar and LBG increases along with kappa blend ratio. Also, originality of gums changes from acidic to alkaline in nature. The $\mathrm{pH}$ value of LBG increases with the blend ratio of 20:80 as 7.31, $40: 60$ as $7.39,60: 40$ as 7.65 and 80:20 as 7.92 which shows moderate increasing level. Similarly, Guar gum increases from 6.49 (20:80), 7.02 (40:60), 7.56 $(60: 40)$ and 7.87 (80:20) respectively. Likewise, Xanthan gum has 6.56, 7.07, $7.33 \& 7.44$ respectively. Also, Sodium alginate showed some narrow changes in the $\mathrm{pH}$ level. But in Gelatine, $\mathrm{pH}$ ranges from 5.65, 6.16, 6.6 and 7.23 as the level of kappa-carrageenan increases. They show quite high changes from the above gums.

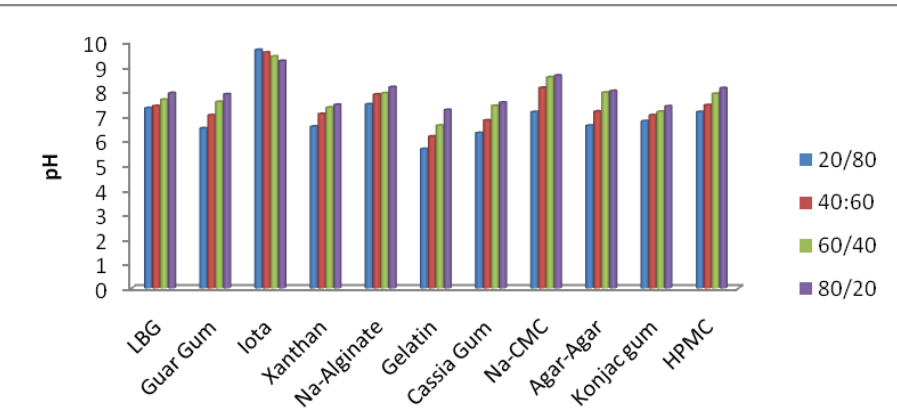

Figure 1 The $\mathrm{pH}$ values of some nano sized food hydrocolloids blended with kappa-carrageenan $(1.5 \% \mathrm{w} / \mathrm{v})$ at $60^{\circ} \mathrm{C}$

The $\mathrm{pH}$ value for combined cassia and kappa carrageenan as follows $6.3,6.81$ 7.4 and 7.53 for 20:80 to 80:20 ratio blends. In the combination of both Na-CMC and HPMC with the kappa carrageenan started with bit alkaline and crossed $\mathrm{pH} 8$ for the 80:20 ratio. The values such as $7.15,7.43,7.89$ and 8.12 for the HPMC fusion with kappa carrageenan in the descending order of kappa and for $\mathrm{Na}$ $\mathrm{CMC}$, the values as $7.15,8.13,8.56$ and 8.63 for descending order blend of kappa with the carboxyl methyl cellulose. Konjac gum and Agar-Agar come under the 
bit acidic category when it's combined with the kappa; it doesn't have made a big change in the $\mathrm{pH}$. The Agar-Agar with the kappa has the values of 6.6, 7.17, 7.94 and 8 for the 20:80 to 80:20 ratios and for the Konjac with the kappa has 6.78, 7.02, 7.16 and 7.38 for the same ratio. From the above discussion on food hydrocolloids with different blend ratio of Kappa carrageenan determines that the level of kappa increases in the blend ratio with gums, the range of $\mathrm{pH}$ decreases the only exception of Iota-carrageenan.

\section{Gel strength}

The gel strength and viscosity are the two important properties depict the quality of hydrocolloids. Only few food hydrocolloids having gel strength individually. As shown in Figure 2, Kappa carrageenan had found the result of gel strength $\left(\mathrm{g} / \mathrm{cm}^{2}\right)$ individually 690 and Agar-Agar had 485. Remaining hydrocolloids couldn't able to form gel individually in a specific period of time. When the food hydrocolloids combined with kappa carrageenan, the results were found different. In the lower value of HPMC with kappa, 120 found in the 40/60 ratio and 350 in the 20/80. Higher the proportion in the kappa content led to form a gel. Likewise, it happened in the kappa combined sodium alginate and Na-CMC. The value 105 found in the 40/60 and 188 found in 20/80 of the ratio between Na-CMC and kappa, 105 found in the combination of sodium alginate with the kappa proportion of 40/60 and 201 for 20/80.Then, Xanthan gum with kappa carrageenan had the lesser effect of 100, 140, 410 for 60/40, 40/60 and 20/80.Next, it was followed by the Iota, Guar and cassia. The ratio of kappa leads to increase of gel strength 136, 263, 417 with Iota carrageenan, 143, 320, 512 with the guar gum in the $40 / 60,60 / 40$ and $80 / 20$.

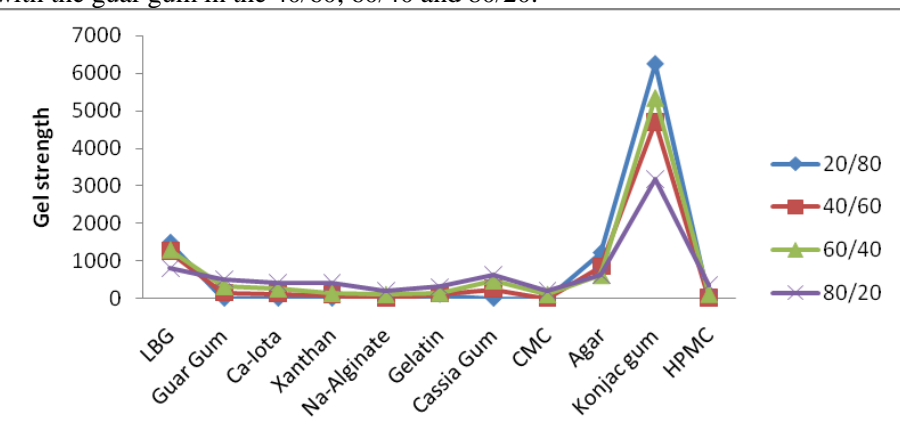

Figure 2 Water gel strength of nano sized food hydrocolloids blended with kappa-carrageenan

The cassia gum with the kappa carrageenan had also found better synergistic effect than the above said hydrocolloids, its values found as 245,470 and 620 for $60 / 40,40 / 60$ and 20/80. The highly used hydrocolloid gelatine with the kappa carrageenan had found the value of 108 for 20/80, 113 for 40/60, 149 for $60 / 40$ and 300 for 80/20.Agar-Agar and Locust bean gum with the kappa carrageenan showed the ascending value that it decreased with the increase of kappa carrageenan. The values such as $1210,839,619,610$ for kappa with Agar-Agar and 1481, 1253, 1302,805 for kappa with LBG in the ratios of 20/80, 40/60, $60 / 40$ and 80/20 respectively. The combination of Konjac with kappa carrageenan had found the high gel strength value due to high synergistic effect. The ratio $40 / 60$ had the value 4690 , the lowest value was found in the $80 / 20$ ratio as 3190 of kappa carrageenan with the Konjac respectively. While the ratio of kappa carrageenan with Konjac in 20/80 proportion showed the highest as 6240 .

\section{Viscosity}

The viscosity of nano sized hydrocolloids plays an important role to improve the quality attributes for the food formulations and medicine formulation. It is mainly characterized by their property of forming viscous dispersions gels when dispersed in water. The viscosity values of all specific hydrocolloids and combination of hydrocolloids showed in Figure 3. Konjac gum have a highest viscous value (cps) of 7800 and followed by Guar gum (7250), Na-CMC (6100), LBG (4700), XG (4500), Na-Alginate (60), Iota-Carrageenan (50), Cassia gum (30), HPMC (12), Kappa-Carrageenan (10), Gelatine (5) and Agar-Agar of 2. Mostly hydrocolloids are bit acidic, so it had an impact on the viscous nature. The individual hydrocolloids viscosity is given heavy changes in the combination. It was related to the theory of synergistic effect. The kappa carrageenan viscosity value of $10 \mathrm{cps}$ showed dominant force against the gelatine and Agar-Agar which have low viscous force. Likewise, it acted as recessive against rest of the gums because of the monstrous level of viscous nature.

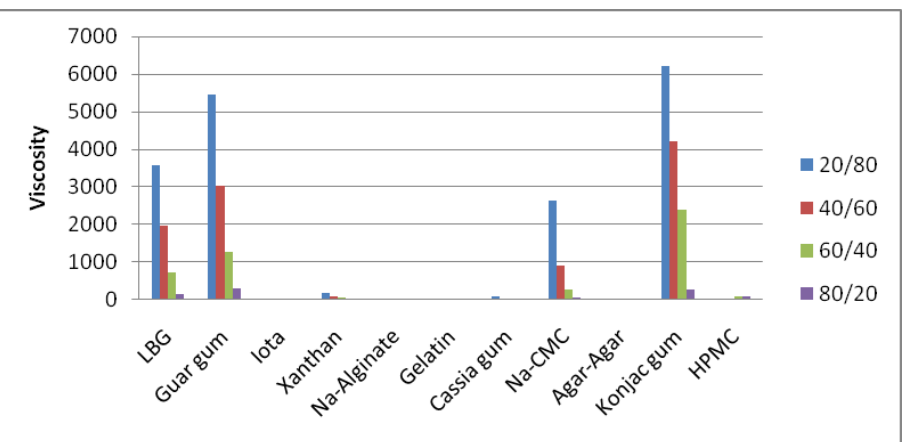

Figure 3 Viscosity of nano sized food hydrocolloids blended with kappacarrageenan

The combination of kappa carrageenan with the other gums depends upon the specific viscosity. The viscous values increased in the ratios of 20:80, 40:60, $60: 40,80: 20$ for the combination of kappa carrageenan with the gelatine and Agar-Agar of 6, 7, 8, 10 and 3,3,4,5 respectively. The sodium alginate was stood as odd value showed different as values got decreased even the sodium alginate viscosity of value 60 .The viscous value of both Iota and cassia with the fusion of kappa carrageenan was maximum related to the individual viscosity of $40,30,20,10$ and 80, 40, 30, 10 for the ratio of 20:80, 40:60, 60:40, 80:20 kappa with Iota and cassia respectively.

The xanthan gum accounts the different zone in an antagonistic value of their individual viscous value "N" number higher than the interactions with the kappa carrageenan and the value depicted as 170, 96, 50 and 15 for the ratio 20:80 to 80:20. Due to the high viscous nature of Na-CMC, it accounts the high in the blend which has $80 \%$ of Na-CMC to the $20 \%$ of kappa carrageenan as 2630 and it simultaneously decreased as 900,280 and 60 for other combination. The Locust bean gum and Guar gum accounts best synergistic effect with the kappa carrageenan as 5470, 3019,1280, 300 for guar and 3570, 1980, 740 and 160 for LBG combinations with kappa carrageenan in the ratios of 20:80, 40:60, 60:40 and 80:20 respectively. The synergistic effect occurs high in between kappa carrageenan and Konjac gum leads to the high viscous nature of combination. The ratio of kappa carrageenan increases with the decrease of viscosity in the Konjac gum combination as 6220 for 20:80, 4200 for 40:60, 2400 for $60: 40$ and 290 for 80:20 of kappa and Konjac gum respectively. In HPMC case, the result is totally opposite as ratio of kappa presence directly proportional to the viscous nature of the combination of gums. It has been increased as $20,40,100$ and 110 for $20: 80$ to $80: 20$.

\section{Viscous Synergism Index}

The synergistic and antagonistic effect of hydrocolloids spoke out the interaction or fusion range of hydrocolloids. If viscosity synergism index $\left(\mathrm{I}_{\mathrm{v}}\right)$ value is between 0 and 0.5 , the viscosity value of fusion of two hydrocolloids will be lower than the viscosity value of the sum of two hydrocolloids and also less than at least one of the hydrocolloid used in the interaction which means that this interaction is antagonism [22]. If $\mathrm{I}_{v}=0.5$, it means that there is nil interaction and if $\mathrm{I}_{\mathrm{v}}$ is between 0.5 and 1.0, it means synergistic interaction happened between two hydrocolloids. Synergistic effect will occur when $\eta_{i}+j>\eta_{i}$ and $\eta i+j>\eta_{j}$. If $\mathbf{I}_{v}$ is higher than 1.0, the viscosity of interaction of two hydrocolloids will be higher than the sum of the viscosities of the two hydrocolloids and synergism will occur.

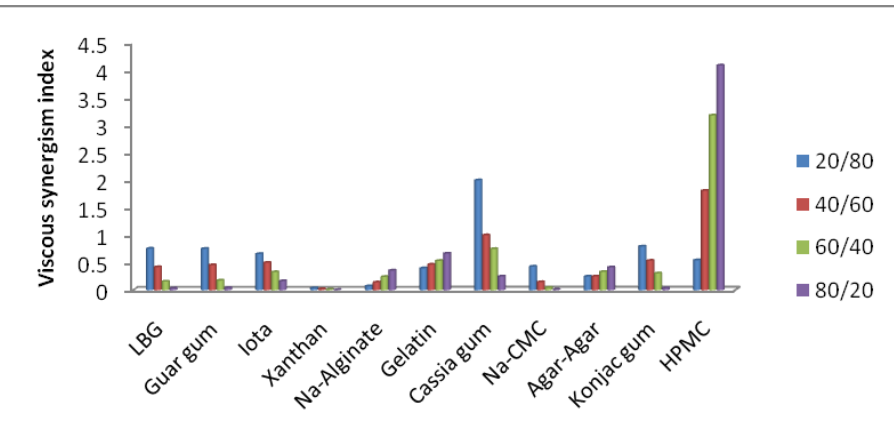

Figure 4 Viscous synergism index of nano sized food hydrocolloids blended with kappa-carrageenan

The synergistic effect combined hydrocolloids as shown in Figure 4. The blend ratio of kappa carrageenan (20) into the LBG, Guar gum, Iota carrageenan (80) individually had best synergistic effect in the rate of $0.757,0.753$ and 0.660 . Among these three, LBG has possible similar characteristics with the kappa carrageenan than the other two hydrocolloids resulting to the high synergism index. The remaining ratio level between the kappa carrageenan with the LBG, guar gum and Iota carrageenan has shown the antagonistic effect. In the case of 
xanthan, sodium alginate, Agar-Agar and carboxyl methyl cellulose found to have the full antagonist effect with the fusion of kappa carrageenan. In the different aspect, gelatine comes under the unique category that has shown synergistic effect as 0.666 in the ratio of 80:20 of kappa carrageenan and gelatine respectively and the other ratios blend showed the antagonist effect. It elaborates that concentration of kappa carrageenan increases in a blend with the gelatine, the synergism value increases. Finally, in the cassia and kappa carrageenan blend the maximum ratios such as 20:80,40:60 and 60:40 depicted the synergistic effect and last one 80:20 cassia and kappa carrageenan showed the antagonism index.
Incorporation of Kappa carrageenan with selected nano sized hydrocolloids provided an increment in their apparent viscosity. Eq.1 and Eq. 2 were used for the prediction of apparent viscosity for the selected hydrocolloids mixture and compared with experimental values which shown in Table 2(a-d). Generally, it was found different values between measured and computed leads to conclude that mixture was not that much fit.

Table 2a Estimation of apparent viscosity of kappa carrageenan blended with some nano sized food hydrocolloid solution using binary mixture model

\begin{tabular}{|c|c|c|c|c|c|c|c|c|c|}
\hline \multirow{3}{*}{ Blend } & \multirow{3}{*}{ Measured } & \multicolumn{2}{|l|}{ Guar Gum } & \multirow{3}{*}{ Measured } & \multicolumn{2}{|l|}{ LBG } & \multirow{3}{*}{ Measured } & \multicolumn{2}{|l|}{ CMC } \\
\hline & & Eq.1 & Eq.2 & & Eq.1 & Eq.2 & & Eq.1 & Eq.2 \\
\hline & & Computed & Computed & & Computed & Computed & & Computed & Computed \\
\hline $20: 80$ & 5470 & 5802 & 1941 & 3570 & 3762 & 1372.2 & 2630 & 4882 & 1690.5 \\
\hline 40:60 & 3019 & 4354 & 520 & 1980 & 2824 & 400.95 & 900 & 3664 & 468.86 \\
\hline 60:40 & 1280 & 2906 & 138 & 740 & 1886 & 117.14 & 280 & 2446 & 130.02 \\
\hline $80: 20$ & 300 & 1458 & 37 & 160 & 948 & 34.227 & 60 & 1228 & 36.06 \\
\hline
\end{tabular}

Table 2b Estimation of apparent viscosity of kappa carrageenan blended with some nano sized food hydrocolloid solution using binary mixture model

\begin{tabular}{|c|c|c|c|c|c|c|c|c|c|}
\hline \multirow{3}{*}{ Blend } & \multirow{3}{*}{ Measured } & \multicolumn{2}{|l|}{ Iota } & \multirow{3}{*}{ Measured } & \multicolumn{2}{|l|}{ Xanthan } & \multirow{3}{*}{ Measured } & \multicolumn{2}{|l|}{ Alginate } \\
\hline & & Eq.1 & Eq.2 & & Eq.1 & Eq.2 & & Eq.1 & Eq.2 \\
\hline & & Computed & Computed & & Computed & Computed & & Computed & Computed \\
\hline 20:80 & 40 & 42 & 36.21 & 170 & 3602 & 1325.3 & 25 & 50 & 41.9 \\
\hline 40:60 & 30 & 34 & 26.25 & 96 & 2704 & 390.63 & 17 & 40 & 2929 \\
\hline 60:40 & 20 & 26 & 19.03 & 50 & 1806 & 115.12 & 10 & 30 & 20.47 \\
\hline $80: 20$ & 10 & 18 & 13.79 & 15 & 908 & 33.93 & 5 & 20 & 14.3 \\
\hline
\end{tabular}

Table 2c Estimation of apparent viscosity of kappa carrageenan blended with some nano sized food hydrocolloid solution using binary mixture model

\begin{tabular}{|c|c|c|c|c|c|c|c|c|c|}
\hline \multirow{3}{*}{ Blend } & \multirow{3}{*}{$\begin{array}{l}\text { Measur } \\
\text { ed }\end{array}$} & \multicolumn{2}{|l|}{ Gelatin } & \multirow{3}{*}{$\begin{array}{l}\text { Mea } \\
\text { sure } \\
\text { d }\end{array}$} & \multicolumn{2}{|c|}{ Cassia Gum } & \multirow{3}{*}{$\begin{array}{l}\text { Meas } \\
\text { ured }\end{array}$} & \multicolumn{2}{|l|}{ Agar } \\
\hline & & Eq.1 & Eq.2 & & Eq.1 & Eq.2 & & Eq.1 & Eq. 2 \\
\hline & & Computed & Computed & & Computed & Computed & & Computed & Computed \\
\hline $20: 80$ & 6 & 6 & 5.74 & 80 & 26 & 24.06 & 3 & 3.6 & 2.757 \\
\hline $40: 60$ & 7 & 7 & 6.59 & 40 & 22 & 19.32 & 3 & 1.6 & 3.805 \\
\hline $60: 40$ & 8 & 8 & 7.57 & 30 & 18 & 15.51 & 4 & 6.8 & 5.251 \\
\hline $80: 20$ & 10 & 9 & 8.70 & 10 & 14 & 12.45 & 5 & 8.4 & 7.247 \\
\hline
\end{tabular}

Table 2d Estimation of apparent viscosity of kappa carrageenan blended with some nano sized food hydrocolloid solution using binary mixture model

\begin{tabular}{|c|c|c|c|c|c|c|}
\hline \multirow{3}{*}{ Blend } & \multirow{3}{*}{ Measured } & \multicolumn{2}{|c|}{ Konjac gum } & \multirow{3}{*}{ Measured } & \multicolumn{2}{|l|}{ HPMC } \\
\hline & & Eq.1 & Eq.2 & & Eq.1 & Eq.2 \\
\hline & & Computed & Computed & & Computed & Computed \\
\hline $20: 80$ & 6220 & 6242 & 2057 & 20 & 12 & 12 \\
\hline $40: 60$ & 4200 & 4684 & 543 & 40 & 11 & 11 \\
\hline $60: 40$ & 2400 & 3126 & 143 & 100 & 11 & 11 \\
\hline $80: 20$ & 290 & 1568 & 38 & 110 & 10 & 10 \\
\hline
\end{tabular}

\section{Functional properties}

\section{Water-Holding Capacity (WHC) and Oil-Holding Capacity (OHC)}

Water-Holding Capacity (WHC) and Oil-Holding Capacity (OHC) of selected nano sized hydrocolloids shown in Figure 5.WHC can be varied depends upon the types of gums and their nature. It was observed that Kappa carrageenan $(46.31 \mathrm{~g} / \mathrm{g})$ had the highest WHC compared to all other hydrocolloids, while HPMC showed least value $2.20 \mathrm{~g} / \mathrm{g}$ of WHC. For the case of OHC, Na-CMC marked the highest value of 4.39 and in the extent, Gelatine had the lowest value of $2.44 \mathrm{~g} / \mathrm{g}$.

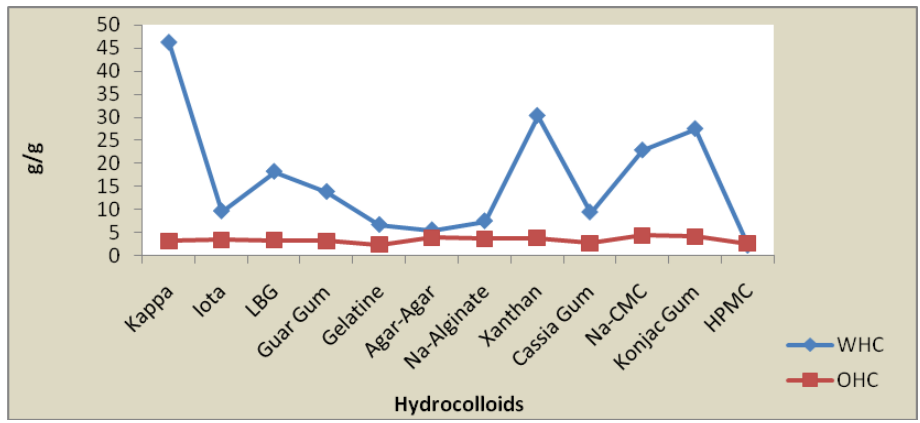

Figure 5 WHC \& OHC of nano sized food hydrocolloids blended with kappacarrageenan

\section{Emulsifying activity (EA) and Emulsion stability (ES)}

Figure 6 shows the EA and ES of selected nano sized hydrocolloids. Xanthan $(62.12 \%$ \& $98.14 \%)$, Guar gum $(62.10 \%$ \& $76.16 \%)$, Konjac $(60.14 \%$ \& $93.14 \%)$ were accounted best emulsion activity and emulsion stability respectively. While Iota carrageenan and Agar-Agar had the minimum value in both EA and ES.

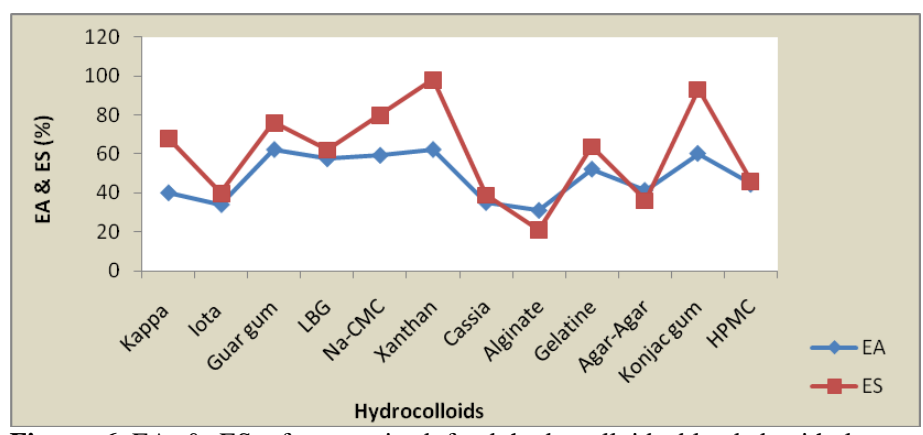

Figure 6 EA \& ES of nano sized food hydrocolloids blended with kappacarrageenan

\section{CONCLUSION}

As a nano sized food hydrocolloids are finding increasing applications in severa foods, and pharmaceutical products as gelling agents, thickening and stabilizing agents. The thickening and gelling effects are mainly provided by sodium 
alginate, carrageenan, hydroxypropylmethyl cellulose, locust bean gum, agaragar and konjac gum. The frequently used thickening and stabilizing agent include xanthan gum, iota and guar gum. The physio-chemical, rheological and functional characteristics of each and combined food hydrocolloids were evaluated. This study suggests that nano sized food hydrocolloids have a lot of potential in nano bio-medicine, bio-nanotechnology, pharmaceuticals and Food industries.

Acknowledgments: Authors are very grateful to Mr. Abhiram Seth, MD, Mr Arun Patnaik, CEO and Mr.Tanmaye Seth of AquAgri Processing Private Limited for their constant encouragements, guidance and facilities created for the present investigation.

\section{REFERENCES}

Bates, T.R., \& Carrigan, P.J. (1975). Apparent absorption kinetics of micronized griseofulvin after its oral administration on single- and multiple-dose regimens to rats as a corn oil-in-water emulsion and aqueous suspension. Journal of $\begin{array}{llll}\text { Pharmaceutical Science, } & 64, & 1475-1481 .\end{array}$ http://dx.doi.org/10.1002/jps.2600640910

Chau, C.F., Cheung, P.C.K., \& Wong, Y.S.(1997). Functional properties of protein concentrate from three Chinese indigenous legume seeds. Journal of $\begin{array}{llll}\text { Agricultural Food } & \text { Chemistry, } & 45, & 2500\end{array}$ http://dx.doi.org/10.1021/jf970047c

Constantinides, P.P.(1995). Lipid micro emulsions for improving drug dissolution and oral absorption: Physical and biopharmaceutical aspects. Pharmaceutical Research, 12, 1561-1572. http://dx.doi.org/10.1023/a:1016268311867

Huang, Q., Yu, H., \& Ru, Q. (2010). Bioavailability and delivery of nutraceuticals using nanotechnology. Journal of Food Science, 75(1), 50-57. http://dx.doi.org/10.1111/j.1750-3841.2009.01457.x

Kayacier, A., \& Dogan, M. (2006). Rheological properties of some gums-salep mixed solutions. Journal of Food Engineering, 72,261-265. http://dx.doi.org/10.1016/j.jfoodeng.2004.12.005

Koocheki, A., Ghandi, A., Razavi, M.A.S., Mortazavi, S.A.T., \& Vasiljevic.(2009). The rheological properties of ketchup as a function of different hydrocolloids and temperature. International Journal of Food Science and Technology, 44,596-602. http://dx.doi.org/10.1111/j.1365-2621.2008.01868.x

Luykx, D.M.A.M., Peters, R.J.B., Van Ruth, S.M., \& Bouwmeester, H.(2008). A review of analytical methods for the identification and characterization of nano delivery systems in food. Journal of Agricultural and Food Chemistry, 56(18), 8231-8247. http://dx.doi.org/10.1021/jf8013926

Mandala, I.G., \& Palogou, E.D. (2003). Effect of Preparation Conditions and Starch/Xanthan Concentration on Gelation Process of Potato Starch Systems International of Journal of Food Properties, 6, 311- 328 http://dx.doi.org/10.1081/jfp-120017818

McClements, D.J., Decker, E.A., Park, Y., \& Weiss, J. (2009). Structural design principles for the delivery of bioactive components in nutraceuticals and functional foods. Critical Reviews in Food Science and Nutrition, 49(6), 577-606 http://dx.doi.org/10.1080/10408390902841529

Ogaji, I.J., Nep, E.I., \& Audu-Peter, J.D. (2012). Advances in Natural Polymers as Pharmaceutical Excipients. Pharmaceutica Analytica Acta, 3,146. http://dx.doi.org/10.4172/2153-2435.1000146

Okaka, J.C., \& Potter, N.N. (1977). Functional and storage properties of cowpeawheat flour blends in bread making. Journal of Food Science, 42,822-833. http://dx.doi.org/10.1111/j.1365-2621.1977.tb12614.x

Pellicer, J., Delegido, J., Dolz, M., Hernandez, M.J., \& Herráez, M. (2000). Influence of shear rate and concentration ratio on viscous synergism. Application to xanthan-locust bean gum mixtures. Food Science and Technology International, 6, 415-423. http://dx.doi.org/10.1177/108201320000600508

Puvanenthiran, A., Goddard, S.J., \& Mekinnon, I.R., \& Augustin, M.A. (2003). Milk-based gels made with $\kappa$-carrageenan. Journal of Food Science, 68,137-141. http://dx.doi.org/10.1111/j.1365-2621.2003.tb14129.x

Rao, M.A.(1999). Rheology of food gum and starch dispersions. In: M.A. Rao, Editor, Rheology of Fluid and Semisolid Foods, Maryland: Aspen, 153-218. http://dx.doi.org/10.1007/978-0-387-70930-7_4

Robertson, J.A., De Monredon, F.D., Dysseler, P., Guillon, F., Amado, R., \& Thibault, J.F. (2000). Hydration properties of dietary fiber and resistant starch: A European collaborative study. LTW-Food Science and Technology, 33, 72-79. http://dx.doi.org/10.1006/fstl.1999.0595

Roopa, B.S., \& Bhattacharya, S. (2009). Alginate gels: rupture characteristics as a function of the conditions of gel formation. Journal of Food Engineering, 91,448-454. http://dx.doi.org/10.1016/j.jfoodeng.2008.09.023

Saha, D. \& Bhattacharya, S. (2010). Hydrocolloids as thickening and gelling agents in food: a critical review. J Food Sci Technol., 47(6):587-597, http://dx.doi.org/10.1007/s13197-010-0162-6

Sahin, H., \& Ozdemir, F. (2004). Effect of some hydrocolloids on the rheological properties of different formulated ketchups. Food Hydrocolloids, 18, 1015-1022. http://dx.doi.org/10.1016/j.foodhyd.2004.04.006
Stanley, N.F. (2006). Agar. In: A.M.Stephen, G.O.Philips, P.A.Williams (Eds). Food polysaccharides and their applications. Boca Raton, Florida; CRC Press. http://dx.doi.org/10.1016/j.carbpol.2006.08.002

Toguchi, H., Ogawa, Y., \& Shimamoto, T.(1990). Effects of the physicochemical properties of the emulsion formulation on the bioavailability of ethyl 2-chloro- 3 [4-(2-methyl-2 phenyl propyl oxyl) phenyl] propionate in rats. Chemical and Pharmaceutical Bulletin, 38, 2797 -2800. http://dx.doi.org/10.1248/cpb.38.2797

Walkenström, P., Kidman, S., Hermansson, A., Rasmussen, P.B., \& Hoegh L.(2003). Microstructure and rheological behavior of xanthan/pectin mixed gels. Food Hydrocolloid. 17, 593-603. http://dx.doi.org/10.1016/s0268 $\underline{005 x(02) 00119-4}$

Williams, P. A., \& Phillips, G. O. (2000). Gum Arabic. In G. O. Philips \& P. A Williams (Eds). Handbook of Hydrocolloids. New York: Woodhead Publishing Limited, 155-168. http://dx.doi.org/10.1533/9781845695873.252

Williams, P.A. (2006). An overview of the structure-function relationship of hydrocolloids. In: G.O.Philips, P.A.Williams (Eds) Gums and stabilizers for the food industry. Oxford: RSC Publication, 13, 15-29. http://dx.doi.org/10.1039/9781847555359-00013 